\title{
Female Leaders' Role Conflict and Its Balanced Solution
}

\author{
Huimin Zheng \\ School of Public Administration and Emergency Management, Jinan University, Guangzhou, China \\ Email:1757649057@qq.com
}

How to cite this paper: Zheng, H.M. (2018) Female Leaders' Role Conflict and Its Balanced Solution. Open Journal of Social Sciences, 6, 226-234.

https://doi.org/10.4236/jss.2018.68018

Received: July 11, 2018

Accepted: August 21, 2018

Published: August 24, 2018

Copyright $\odot 2018$ by author and Scientific Research Publishing Inc. This work is licensed under the Creative Commons Attribution International License (CC BY 4.0).

http://creativecommons.org/licenses/by/4.0/

\begin{abstract}
With the transformation of society and the improvement of occupational diversification, women's awareness and the ability of political participation are constantly strengthening. The proportion of female leading cadres in China is also growing year by year; however, as far as the development of female leading cadres is concerned, women are still far behind men in terms of quantity and behavioral influence. The long-term status inequality has inhibited women's instinct and desire to tap their own potential and the sense of social participation. The career development and life balance of female leaders under multiple role conflicts has become the confusion of most female leaders. Therefore, mastering the balance of female leadership role conflicts is of great significance for improving women's leadership and creating a happy life.
\end{abstract}

\section{Keywords}

Role Conflict, Female Leader, Balanced Solution

\section{Introduction}

It is a challenging and uncertainty world which is full of opportunities and competition. The special group-female leaders have the same social mission as male leaders; however, due to kinds of differences in gender roles and social roles, female leaders have encountered some barriers that cannot be ignored in their further career development.

\section{Types and Manifestations of Female Leaders' Role Conflicts}

In the big arena of society, each person usually plays multiple roles at the same time. The interpretation of different roles is often inconsistent with the require- 
ments of individuals, which is subject to the conflict of individual time allocation, the limited energy and the contradiction of goals. These lead to multiple role conflicts for female leaders. In short, Types and manifestations of female leaders' role conflicts are as shown following:

\subsection{Conflict between Traditional Female Characters and Female Leaders}

Driven by the modernization process, the political, economic, cultural, and social rights enjoyed by Chinese women have changed dramatically in the night of the alternation of old and new societies. It is obvious that the women's thoughts have been liberated and the women's status has been advanced. However, the traditional concepts from China, more than two thousand years of feudal traditional culture, such as "women's incompetence is virtue", "male outside, female inside", "good wife and good mother", still affect the perception and evaluation for women, even more, people think it is wrong for women to be frank, aggressive, and more powerful than men. To a certain extent, it will strengthen female leaders' inferiority, which has fostered women's psychology of being comfortable with the status quo, and conflicting with the spirit of being innovated.

\subsection{Conflict between the Role of Female Gender and Female Leadership}

For a long time, people's different expectations for different genders seem to set a behavioral circle for the men and women. During the growth process, men are more encouraged to go out and struggle, while women's ears are full of more sound, such as, the family should be the most important, while the work is secondary . Professor Deborah Grandfair, a professor of leadership and organizational behavior at Stanford University, once said: "Our deep-rooted cultural traditions associate men with leadership traits, while associating women with tending traits, which make women into a dilemma, and we believe that it is women primary role to act as the tenderers. If a woman is not easy-going, she will make a negative impression and make others feel uncomfortable." [1] Besides, people thought that men are more suitable for leadership positions than women, which greatly affects and even hinders the development of female leaders, which produced different evaluation criteria for men and women. For example, men can have a successful career and a satisfactory personal life. However, it is difficult for women to balance her work and family, which make themselves unbearable and get into trouble.

\subsection{Conflict between Job Requirements and Work Ability of Female Leaders}

It usually positions the female leaders' job function as an interpersonal role or an information transmitter in the workplace, while men are mostly play the role of decision-making. The combination of female leadership and power is often the edge of power is higher than the core power. In China, there are often such jin- 
gles when it comes to women's leading cadres: “There are many older people, less younger, more deputy, less formal; fewer posts, more groups and departments, and the main line of the party and government and the main battlefield of the economy are less." [2] At the same time, the proportion of women in all levels is gradually decreasing, therefore, we can know that the female leaders will face considerable obstacles. In addition, in order to meet the proportion of women in the policy leadership group, some women who are lacking in leadership ability can promoted to the leadership team. However, these female leaders have less work experience than men, being accustomed to doing things step by step, lacking awareness and attention to strategic issues and major decisions of organizational development, which will be prone to dependency and working as a supporting role in the work. This incompetent phenomenon puts pressure on the work of female leaders, which is not conducive to their career development.

\subsection{Conflict between the Role in the Family and Workplace of Female Leader}

In the traditional division of housework, it is usually think that women should do the housework or only women can take responsibility for doing housework. However, it is true in the actual division of family life. According to 2010, The Chinese Women's Social Status Survey report shows that there is a significant difference in the average daily housework time between men and women. In towns, men spend an average of 43 minutes per day on housework and $102 \mathrm{mi}$ nutes on women, about 2.4 times that of men. In rural areas, men spend an average of 50 minutes a day on house and 143 minutes on women, about 2.9 times more than men. Both the man and Women adhere to the standard working hour system of 8 hours a day, but compared with men, women face more problems such as long working hours, busy domestic work, caring for the elderly and children, and have more obvious conflicts in work and life [3]. For a female leader who is married or been a mother, it is usually unable to bear the responsibility of being a wife or mother, because they have to deal with the tasks, that will be occupied their too much time, which will make many female leaders tired or exhausted. At the same time, when a wife's social status and professional prestige are better than her husband, female leaders are more likely to feel the pressure from her husband's psychological imbalance and external criticism, and the man has to do the housework that was originally undertaken by the female. It is easy to have conflicts if they have a poor communication.

\subsection{Conflict between the Female Character and the "Masculine" Leadership Style}

Men and women have differences in their innate personality. Compared with men, women are born with gentle, delicate and sensitive. These personality characteristics make women have obvious advantages in procedural and transactional work. However, being a leader should be supposed to be owe the abilities of strategic, farseeing, direction guidance, and rulemaking. These abilities are 
often considered to be held by men [4]. If female leaders fail to actively develop these qualities and abilities in their work development, they will be questioned by their leadership. When women try to make themselves a masculine personality image to establish leadership prestige that is, when they are strong or decisive or competitive, the people around them will think that she is deviating from her internal characters. If a woman is too close to the work schedule, if she is very capable, if she focuses on the outcome rather than please others, if she acts like a man, people will not like her. A woman who is called a "strong woman", "iron rose" or "female man" is never a positive evaluation for her.

\section{The Adverse Effects of Improper Handling of Female Leadership Roles}

As the bearer of multiple roles, female leaders are faced with the reality of frequent role adjustment and switching. They face the influence and constraints of many factors from the outside world. If they can't properly handle these multiple role conflicts, it is easy to bring a series of adverse effects for women.

\subsection{Affecting Female Leaders' Reputation}

If female leaders are unable to properly handle conflicts between being a wife or mom and being a leader due to subjective or objective reasons at work, it is easy to arouse members' suspicion and dissatisfaction. In addition, if female leaders devote too much energy for their work, it is very easy to arouse controversy and criticism. Which affects the reputation of women leaders to a certain extent, and be not conducive to their personal image, which makes it difficult for women leaders to establish prestige and influence the development of leadership.

\subsection{Affecting the Career Development of Female Leaders}

The career path of women, due to external barriers or internal barriers, is somewhat more rugged than men. On the one hand, women face many obstacles in the workplace, including gender discrimination, differential treatment and negative feedback. On the other hand, women who internalize gender concepts and traditional culture are used to playing a secondary role instead of acting as a decisionmaker, and gradually reduce the expectations of what they have achieved. These factors in the short-term may cause female leaders to be inefficient in their work, affecting the development and completion of specific affairs, which will affect the future career development of women leaders in the future.

\subsection{Affecting Female Leaders' Family Harmony}

Female leaders have to take care of their careers and family at the same time. The conflict will be not too obvious if the gap between female leaders and their partners is not large, but it is inevitable that the men will be dissatisfied with their wife that they fail to achieve the role of the family. Moreover, if the position title of female leaders is higher than their husband, the men still sticks to the tra- 
ditional view, the men will be dissatisfied with his wife because that their self-esteem is facing a great challenge, and losing their value in his career development. Therefore, the gap between the husband and the wife will be quietly born, gradually affect the marital relationship and family life, even lead to the marriage breakdown. Therefore, many female leaders have chosen their careers, but giving up their families or simply choose to unmarried, being a single-person. For example, former Vice Premier Wu Yi has been unmarried because of his self-denial of work and idealism of love.

\section{The Cause of Female Leaders' Role Conflict and Balance Dilemma}

\subsection{Traditional Ideas Are Biased against Female Leaders}

The prejudice of traditional ideas influences the social evaluation criteria for female leaders and questions the abilities of female leaders. For thousands of years, the traditional moral values such as "male outside, female inside" and "Innocence is the virtue for women" have negated women's self-worth and self-development needs, women find it is too difficult to break free from bondage completely, even in the increasing participation modern society. People expect that women should be virtuous, and the family should be primary in their eyes. When people talk about the leadership, they are often linked to male in place of female. The conflict of expectations in this role makes female leaders often face external prejudice, like female leaders will not as good as men. This is not only questioning female leaders' abilities, but also denying their potential of future work. As a result, it seems that the society has created a fair phenomenon for the female leaders and they have entered a new world where used to exit only men. However, female cannot change the gender class and the traditional values in reality, in order to cater to such values, many women tend to play a role in Iron Lady, which is contrary to the society's expectation of women's gender image. It leads to that women usually tap into a balanced dilemma.

\subsection{Irreconcilable Contradiction between the Characters of Female and Leaders}

In addition to the limitations and prejudices of women in traditional society, there are also subjective factors that are constrained by the innate differences between female roles and leadership roles. Which leads to most of the leadership positions were carried out by men rather than women. It is undeniable that the ability, methodological skills and experience qualifications of female leaders are generally inferior to men. The main reason is the limitations of their physiology and the psychological vulnerability. On the one hand, women are more likely to be emotional. When faced with difficult tasks and complicated situations, they often have anxiety and irritable emotions, which are easy to be depressed or self-blame, and they often attribute failure to themselves and tap into the circle of self-doubt. On the other hand, women would be more depend than men, if 
they can't properly grasp themselves, they can easily fall into an over-reliance situation, which makes female leaders lack of independent consciousness and autonomy in a pinch. A charming leader should have an extraordinary rational thinking, strategic vision and independent judgment, these characters are difficult to reconcile the characters of female, such as more emotional, more dependent than men, which would affect their capacity to make decisions and the ability to lead their followers.

\subsection{Female Leadership's Own Role Recognition Influences Leadership}

The recognition of female leaders will influence the performance of women's leadership. Different from the far-reaching influence and penetration of the Western feminist movement, the promotion of women's status in China is first advocated at the national level. The majority of female groups who have been restrained in the traditional shackles directly skip the process of spontaneous liberation struggle and largely lack of subjective initiative. Some female leaders have been pushed to be the leaders due to several other reasons, and they are not ready to be leaders, and aren't fully endorse the female leaders, which would make them discomfort. In addition, these female leaders lacked appropriate experience before being a leader. During their tenure of office, they lacked systematic training. Which caused that they were unable to bear the pressure. While being a leader, especially the female leader, will attract more attention and evaluation from the outside world, and it will bring a heavy psychological burden to female leaders.

\subsection{Negative Impact from the Misunderstanding of Family Members}

The pressure from family members can magnify the role conflict for female leaders. In our country, deeply influenced by the traditional conservative concept, men should bear the responsibility of supporting the family. A successful man will not only be measured by money, but also being compared with their wives. Moreover, the husband's career will be more successful than his wife in a happy marriage. When women's career development is better than men, and their social status is not equal. It is easier to bring the conflicts for couple. And the female would suffer more emotional and spiritual damage. In addition, in the face of the reality that the housework is mainly done by family members. If women do not have the family members' supporting in housework at home. On the one hand, women leaders will not be devoted herself into work because of domestic work. On the other hand, female leaders often need to work overtime or on business trips because of work, and they will be incapable of taking care of their family.

\subsection{Affect the Female Leaders' Distribution of Time and Energy Because of their Different Roles}

Time and energy are always limited for people. You can't have your cake and eat 
it. Female leaders can't meet different role expectations at the same time. In order to have a better leadership, female leaders have to spend a lot of time and energy in their jobs. However, Women spend lots of time and energy in housework, her husband's living arrangements, her child's education, and taking care of elders. What's worse, there are frequent conflicts in women's time arrangement, such as they can't reconcile the time among her career development, companying her children and husband. When they face these dilemmas, women must make a choice and sacrifice to meet the needs of the other side. It often brings a heavier psychological burden to women.

\section{Solutions to Ease the Multiple Roles Conflicts of Female Leaders}

\subsection{Balanced Solution of Having a Strong Psychological Quality}

Female leaders should develop a good psychological quality and improve the ability to deal with role conflicts, and they should learn to express their own psychological cues, adjust their mentality, and respond to the contradictions of multiple roles with a peaceful heart. When dealing with conflicts between family roles and job roles, trying to get the result of satisfactory rather than perfect. Everyone is always making choices between the career and family about the distribution of time and energy, trying to do everything and expecting to be perfect, which will inevitably lead to be disappointed, so female leaders should put down their demands, many things only need to complete, instead of being perfect, which would ease the psychological burden of role conflicts; in addition, female leaders must learn to ignore the negative views and evaluations about the conflict between the characters of traditional women and the modern female leaders. Don't care about judgment from other people's criteria, be brave to achieve our own goals, which can reduce the interference on their emotion.

\subsection{Balanced Solution of Being Considerate of Everything}

Female leaders should be good at making overall arrangements, strengthening the adjustment between the role of a woman and a leader, when people doubt that women were not suitable for being a leader. In the article "The Working Methods of the Party Committee", Comrade Mao Zedong compared the effective work of leading cadres to "playing the piano". He emphasized that "playing the piano requires ten fingers to move, but ten fingers are pressed at the same time, it isn't work. To produce good music, the movements of ten fingers must have rhythm and cooperate with each other." [5] Female leaders must learn to coordinate the overall situation, analyze the urgent tasks scientifically, handle the relationship between comprehensive work and key work, and distinguish between major contradictions and secondary contradictions. Most importantly, they should have a precise judgment on the work, clearly understand the advantages and personality characteristics of each organization member, achieve a reasonable division of labor, and be good at coordinating. Female leaders should 
explore and learn in specific affairs, constantly improve their work skills and leadership skills, and eliminate the external doubts about their own leadership skills through the excellent work performance and resolve the conflicts gradually.

\subsection{Balanced Solution of Making Decision Selectively}

Willing, willing, there are homes only have. When faced with the contradiction of multiple roles, female leaders should set a standard for their own choices, learn to prioritize and make a more meaningful choice through their rational judgments. It is an effective way to avoid multiple role conflicts. For example, in the workplace, when people have prejudice against female leaders' gender and personality, female leaders can choose to ignore the evaluation. Remembering, the best way to change the bias of others is to prove yourself with your abilities and achievements. And the only standard to decide your leadership style is not catering for others opinion, just choose the best way to solve the difficulties for the development of organization. Although, selective decision-making seems to have abandoned some aspects, but on the other hand, gaining more achievements can balance the regrets of what lose.

\subsection{Balanced Solution of Communicating}

Making good use of communication art is conducive to alleviating the negative impact of work and family role conflicts for female leaders. Women are born with great advantages in communication and self-expression. Female leaders should make full use of these advantages to win the trust from your superiors, colleagues and subordinates, and be good at expressing the love in the family, which can gain more understanding and supporting from the family members.

In addition to the formal communication methods, such as meetings and reports, female leaders can also care about their subordinates on their own initiative through other informal communication methods. Which can enhance mutual understanding during the conversations and win the recognition from subordinates. Most importantly, female leaders must be brave in seeking help and guidance from their superiors when encountering the difficulties that are difficult to resolve, because it will be more conducive to solve problems; when communicate with family members, it is necessary to make a concession properly. More praise and encouragement, less anger and accusation, and female leaders should be good at defending the husband's image status, sharing the difficulties in the work with the husband and seeking his advice, so that the husband can feel that he is important and be needed. which would maintain a good relationship and create a harmonious family phenomenon.

\subsection{Balanced Solution of Paying}

No caring too much about what we have gained and lost, just seeking the meaning of life about devotion. The maternal nature of women makes them usually more benevolent and selfless. This kind of paying characteristics is necessary for 
the organization and operation of the new era in some extent, because female leaders often appear to be dedication, enthusiasm, love, and open-minded, which make people who work with them will be easier convinced and support female leaders, thus guiding the entire organization in a positive atmosphere. On the other hand, women's dedication and care for the family are almost instinctive. If improve their own ideological realm, no longer stuck to the contradictions and conflicts, and rise to a higher level to solve the problem. No caring about the division of family chores, tolerating the incomprehension from family members, watering the family's garden with selfless. In the long run, the family can feel the greatness of female leaders, and thus would give back more understanding to women, and female leaders will be surrounding by fortunate.

\section{Conclusion}

Although female leaders have to face more role conflicts than male leaders, the female leaders should solve these difficulties rationally, establish a balanced solution systematically, and keep a balance between life and work, which can satisfy demands from the society.

\section{References}

[1] Sandberg, C. and Scoville, N. (2014) Step Forward: Women, Work and Leadership Will: A New Upgraded Collector's Edition. CITIC Publishing House, 31.

[2] Jiang, L. (2009) Looking at the Obstacles of Female Leadership Development from a Gender Perspective. Leadership Science, 21, 44-45.

[3] The Third Phase of the Chinese Women's Social Status Survey Group (2011) The Third Phase of the Chinese Women's Social Status Survey Main Data Report. Women's Studies, 6, 5-15.

[4] Li, J. (2012) Analysis of Non-Institutional Barriers and Countermeasures of Female Leadership Improvement. Women's Studies, 4, 102-105.

[5] Jia, Z.G. (2016) The True Meaning of the "Playing the Piano" Leadership Art. Friends of Leadership, 8, 10-11. 